\title{
Void growth in high strength aluminium alloy single crystals - A CPFEM based study
}

\author{
Umair Asim $^{a}$, M. Amir Siddiq ${ }^{a,}$, Murat Demiral $^{b}$ \\ ${ }^{a}$ School of Engineering, University of Aberdeen, Fraser Noble Building, AB24 3UE, Aberdeen, UK \\ ${ }^{b}$ Department of Mechanical Engineering, Çankaya University, 06810 Ankara, Turkey \\ "Corresponding Author: amir.siddiq@abdn.ac.uk
}

\section{Abstract}

High strength aluminium alloys are widely used in aerospace components which are produced through forming and joining processes. The ductile failure in these metals occur due to the evolution and accumulation of microscopic defects, such as micro-voids and shear bands. Present work investigates the underlying physical mechanisms during ductile failure by performing a rigorous fully-validated three dimensional crystal plasticity finite element studies in aluminium alloy single crystals. Representative volume element (RVE) based simulations of single crystalline aluminium alloys (AA-5xxx) with different void geometries and orientations have been performed. Both local and nonlocal crystal plasticity constitutive models have been implemented in finite element framework and are used to seek new insights and interrelationship among void growth, initial porosity, initial void size, plastic anisotropy, and local/nonlocal size effects.

\section{Keywords:}

Void growth; non-local crystal plasticity theory; Single crystal aluminium alloy; Lattice rotation

\section{Introduction}

Aluminium alloys are typically used in a variety of applications, which require light weight, high strength, corrosion resistance and formability. The 5xxx family of aluminium alloys are under investigation for some time due to their significant strength increase resulting from precipitation and hence are widely used in welded structures and formed parts. Fractography of these alloys have shown that the fracture initiation due to void nucleation, growth and coalescence is one of the main mechanism of failure [1,2].

The research on void nucleation, growth and coalescence during ductile damage of metals and alloys dates back to late 1950's. In the following, we provide a brief review of the research in this area to date. The research can be classified into different types based on the used approach; such as analytical studies, finite element based modelling using either macroscale isotropic plasticity models or crystal plasticity based modelling, finite element based studies using non-local theories, and dislocation dynamics models. All of these are discussed briefly (in the same order) in the following and readers are requested to see the references for detailed discussion. 
It was reported that the nucleation and growth of microvoids are the main reasons in the ductile damage of metals [3-5]. McClintock [6] performed theoretical study of the expansion of long cylindrical defect with circular cross section in an ideal plastic material with no hardening. Rice and Tracey [7] performed theoretical investigations to determine the relationship between spherical void growth and stress triaxiality in an elastically rigid, incompressible and non-hardening continuum plasticity framework. Needleman [8] showed the significance of void interaction effects in a double array of circular cylindrical voids under plane strain tensile loading. Nemat-Nasser and Hori [9] presented analytical solution for plane problems with large deformation in porous crystalline solid undergoing void growth or collapse. Liu et al. [10] performed analytical studies to understand the size effects on void growth by extending Rice and Tracey [7] model. Kysar and Gan [11,12] used anisotropic slip line theory to derive relationships for the stress and deformation state around a cylindrical void in a single crystalline matrix. Li and Steinmann [13] performed studies on different types of spheroidal voids in an axisymmetric spheroidal unit cell to explain the effect of void size and shape on deformation behaviour of materials with microvoids.

Andersson [14] performed numerical studies on plane strain single void cell under uniaxial deformation with a rigid-plastic material. Tvergaard [15] studied the effect of microvoids during ductile failure of material by investigating an elastic-plastic solid with a periodic array of circular cylindrical effects. Li and Howard $[16,17]$ performed finite element analyses to understand the growth of a spherical void in an elastic-plastic material. Bourcier et al. [18] performed experimental and analytical studies (plane strain) to understand the effect of porosity on the deformation and fracture behaviour of Titanium alloys. Koplik and Needleman [19] presented numerical solutions to predict the influence of an array of voids in a axisymmetric cell model. Hom and McMeeking [20] performed three dimensional finite element analyses to investigate the porosity evolution in a cell with cubic arrays of void. Worswick and Pick [21] performed finite element based studies to investigate the void growth and constitutive softening in three dimensional framework. Needleman et al. [22] performed finite element based analyses on an axisymmetric cell model with spherical voids. Kuna and Sun [23] performed three dimensional analyses to understand the damage due to void growth. Tvergaard and Hutchinson [24] performed plan strain analyses of material with voids located ahead of a crack-tip. Li and Guo [25] performed finite element based computations to investigate the void growth and coalescence at the interface in a bimaterial system.

O'Regan et al. [26] performed crystal plasticity based studies to investigate the microvoid growth and coalescence in single crystals using two dimensional plane strain formulation with idealised two dimensional slip system configuration. Orsini and Zikry [27] performed crystal plasticity based analyses to understand void growth and interaction in copper single crystal plates. Ohashi [28] used dislocation based crystal plasticity theory to understand the spherical microvoid growth in single crystalline material. Potirniche et al. [29] performed 
crystal plasticity based finite element simulations on two dimensional unit cells with one and two voids. Liu et al. [30] used crystal plasticity based finite element simulations to investigate the effect of crystal orientation in face centred cubic crystals on void growth and coalescence. Yerra et al. [31] performed three dimensional crystal plasticity based simulations to investigate the void growth and coalescence in body centred cubic crystals. It was reported void growth rate is strongly dependent on the initial crystal orientation and a model to predict the onset of void coalescence was presented. Ha and Kim [32] used crystal plasticity theory to understand the deformation and microvoid growth behaviour of FCC crystals. Huang et al. [33] performed discrete dislocation dynamics based simulations on FCC crystals to understand the cylindrical microvoid growth under biaxial loading. Segurado and Llorca [34] performed discrete dislocation dynamics based simulations in the 2D framework to understand the void size effect in single crystals. Recently Pushkareva et al. [35] have recently presented a remarkable in-situ study of void growth in commercially pure titanium using $x$-ray computed tomography and crystal plasticity simulations. It was reported that void growth is strongly dependent on grain orientation than intervoid spacing and material strength.

Tvergaard and Needleman [36] used a nonlocal damage model to understand the material length scale effects. Tvergaard and Niordson [37] performed axisymmetric nonlocal elasticplastic analyses to understand void size effect. Hütther et al. [38] and Zybell et al. [39] performed plane strain studies to understand the secondary voids size effects during ductile fracture. Shu [40] performed plane strain studies to understand the deformation of single crystal with microvoids using a strain gradient crystal plasticity theory. Huang et al. [41] presented a mechanism-based theory of strain gradient plasticity with applications including microvoids growth. Borg and Kysar [42] studied the presence of cylindrical void in HCP single crystal under biaxial plane strain loading. Borg et al.[43] investigated the growth of different void sizes using strain gradient crystal plasticity theory in a plane strain configuration. Liu et al. $[44,45]$ investigated the void coalescence in single crystals, voids at grain boundary, and voids in two grains using three dimensional crystal plasticity framework.

The presented work moves forward the above efforts by performing a rigorous fullyvalidated 3D CPFEM based RVE study of aluminium alloys AA-5xxx for different void geometries and orientations in single crystalline material. Both local and nonlocal constitutive models have been used to reveal new insights and clearing up the relationship among void growth, initial porosity, initial void size, plastic anisotropy, and local/nonlocal size effects.

\section{Modelling Concept}

This section discusses the overall modelling concept which is based on crystal plasticity theory implemented in finite element framework followed by model validation and description of test matrix for CPFEM based RVE study. 


\subsection{Local and Non-Local Crystal Plasticity Theory}

Conventional crystal plasticity theories account for plastic deformation based on crystalline slip in activated slip system due to dislocation motion. The precise theoretical framework dates back to 1972 by Hill and Rice [46] which has been updated and modified by predecessors $[47,48]$. Other class of crystal plasticity models are based on dislocation evolution relations which ultimately contribute towards crystalline slip (for details please see $[28,49-56]$ and reference therein). Non-local (strain gradient based) models can be classified as lower and higher order theories. In higher order nonlocal models, the order of governing balance equations is increased by including higher-order stress [54,57]. These type of non-local models also require additional boundary conditions. On the other hand lower order nonlocal models do not involve higher order stress and additional boundary conditions [54,57].

In the following a brief summary of the local and nonlocal crystal plasticity formulations used for the present work has been presented. Local crystal plasticity models used are based on Marin [58] and Hill and Rice [46,53]. Non-local model is based on mechanismbased strain gradient theory (MSG) and developed in Han et al. [59] and Demiral et al. [60] while used in Siddiq et al. [54].

\subsubsection{Local Crystal Plasticity Formulation}

As discussed above, this theory is also based on the assumption that elastic-plastic response of single crystalline materials is dominated by the crystalline slip due to dislocation motion and interaction. In the following, we only present the selected constitutive equations related to the slip system kinetics and strength of the model (for detailed discussion and numerical implementation, please see ref $[58,61]$ and references therein.

Plastic slip in $\alpha$-th slip system is given by the conventional crystal plasticity based power law

$\dot{\gamma}^{\alpha}=\dot{\gamma}_{0}\left[\frac{\left|\tau^{\alpha}\right|}{g^{\alpha}}\right]^{1 / m} \operatorname{sgn}\left(\tau^{\alpha}\right)$

where $\tau^{\alpha}$ is the resolved shear stress on slip system $\alpha, g^{\alpha}$ is the strength of the slip system $\alpha, \dot{\gamma}_{0}$ is a reference shear strain rate, and $m$ is the rate sensitivity exponent.

The resolved shear stress $\tau^{\alpha}$ in a specific slip system is computed through deviatoric stress tensor $\sigma^{\prime}$ and Schmidt factor based on slip system direction and normal, $\boldsymbol{s}^{\alpha}$ and $\boldsymbol{m}^{\alpha}$

$\tau^{\alpha}=\sigma^{\prime}:\left(s^{\alpha} \otimes m^{\alpha}\right)$

The evolution of the strength of the slip system is based on the saturation hardening rule and is given by

$\dot{\boldsymbol{g}}^{\alpha}=\boldsymbol{h}_{0}\left(\frac{g_{s}(\dot{\gamma})-g^{\alpha}}{g_{s}(\dot{\gamma})-g_{0}}\right) \dot{\gamma}$

where 
$g_{s}(\dot{\gamma})=g_{s 0}\left(\frac{\dot{\gamma}}{\dot{\gamma}_{s 0}}\right)^{m^{\prime}}$ and $\dot{\gamma}=\sum_{\alpha}\left|\dot{\gamma}^{\alpha}\right|$

while $h_{0}, g_{s 0}, g_{0}, \dot{\gamma}_{s 0}$, and $m^{\prime}$ are material parameters to describe hardening behaviour for all slip systems.

\subsubsection{NonLocal Crystal Plasticity Formulation}

A lower order mechanism-based-strain-gradient crystal-plasticity (MSGCP) theory $[54,59,60,62]$ was used in the simulations. In this theory, strength of the slip system, $g^{\alpha}$, equals to summation of the critical resolved shear stress (CRSS, $g_{0}$ ) and slip resistance due to hardening in the course of loading (Eq. 4).

$g^{\alpha}=g_{0}+\sqrt{\left(\Delta g_{s}^{\alpha}\right)^{2}+\left(\Delta g_{G}^{\alpha}\right)^{2}}$,

The slip resistance during loading evolves with hardening due to the SSDs ( $\left.\Delta g_{s}^{\alpha}\right)$ (Eq. 5) and GNDs $\left(\Delta g_{G}^{\alpha}\right)$ (Eq. 6) on the slip system, where $\alpha, \mu, b$ and $n_{G}^{\alpha}$ corresponds to the Taylor coefficient, the shear modulus, the Burgers vector and the effective density of GNDs, respectively.

$\Delta g_{S}^{\alpha}=h_{0}\left(\frac{g_{s}(\dot{\gamma})-g^{\alpha}}{g_{s}(\dot{\gamma})-g_{0}}\right) \Delta \gamma$

$\Delta g_{G}^{\alpha}=\alpha \mu \sqrt{b n_{G}^{\alpha}}$

Effective GND density $\left(n_{G}^{\alpha}\right)$ is given by

$n_{G}^{\alpha}=\left|\boldsymbol{m}^{\alpha} \times \sum_{\beta} s^{\alpha \beta} \nabla \gamma^{\beta} \times \boldsymbol{m}^{\beta}\right|$

where $s^{\alpha \beta}=\boldsymbol{s}^{\alpha} \cdot \boldsymbol{s}^{\beta}$ and $\nabla \gamma^{\beta}$ is the gradient of shear strain in each slip system [62].

The MSGCP theory was implemented in the implicit general-purpose FE code ABAQUS/Standard using the user-defined subroutines UMAT and URDFIL to represent the material response and to read the results file during the simulation, respectively. A key point in the implementation is the determination of a shear strain gradient $\nabla \gamma^{\beta}$ in Eq. (7). To do this for 3 dimensional 8 noded brick linear C3D8 element, initially within an element level the shear strain values for each slip system, $\alpha$, at each node were obtained using URDFIL. Next, these data were transferred to the UMAT to compute the shear strain gradients at each integration point by calculating the spatial derivatives of the linear shape functions using the scheme described by Busso and co-workers [63].

\subsection{Material Parameter Identification}

Material parameters discussed in the section 2.1 are identified using inverse modelling approach where uniaxial tension test experiments were performed on aluminium alloy(for details please see [64] and references therein). The identified set of material parameters are 
given in Table 1 while a comparison between experimental and simulated response is given in Figure 1.

Table 1: Material Parameters for Aluminium Alloy AA-5xxx

\begin{tabular}{|c|c|l|l|l|l|l|l|l|c|}
\hline$m$ & $\dot{\gamma}_{0}$ & $h_{0}$ & \multicolumn{1}{|c|}{$g_{0}$} & $g_{s 0}$ & $m^{\prime}$ & \multicolumn{1}{|c|}{$\dot{\gamma}_{s 0}$} & $\alpha$ & $\mu$ & $b$ \\
\hline 0.03 & 0.001 & 200.40 & 105 & 110 & 0.0 & $5 \mathrm{e} 10$ & 0.7 & 26400 & $2.8 \mathrm{e}-$ \\
& & $\mathrm{MPa}$ & $\mathrm{MPa}$ & $\mathrm{MPa}$ & & $/ \mathrm{sec}$ & & $\mathrm{MPa}$ & $7 \mathrm{~mm}$ \\
\hline
\end{tabular}

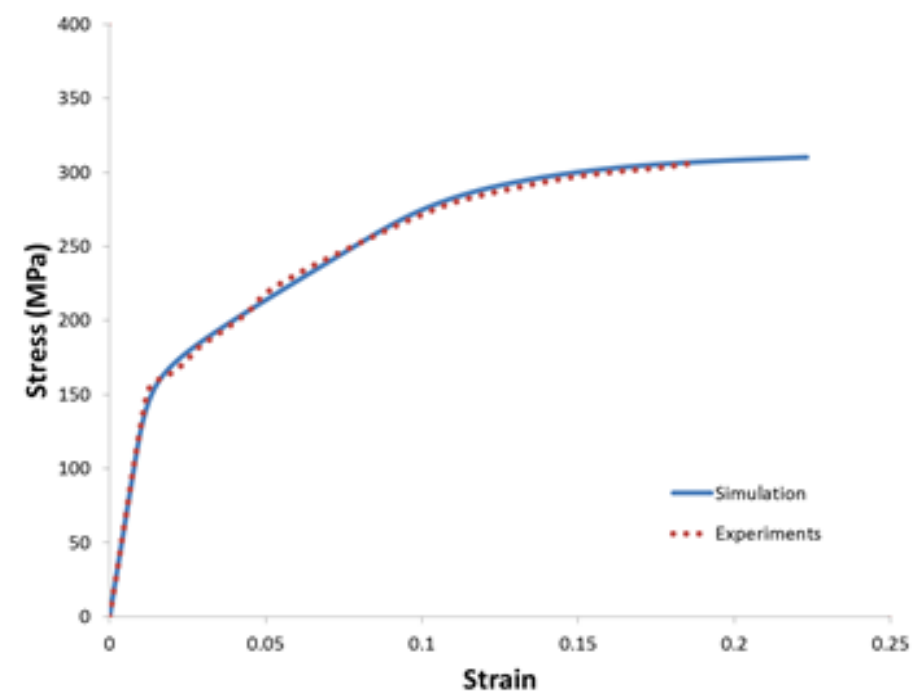

Figure 1: Comparison of Stress-Strain Curves after Material Parameter Identification

\subsection{Test Matrix for RVE based CPFEM Study}

Finite element based three dimensional representative volume element models have been constructed for various void sizes (ranging from $310 \mathrm{~nm}$ to $1.44 \mathrm{~mm}$ ), void shapes (spherical and elliptical) and initial void fractions $(0.001,0.005,0.01,0.03,0.05)$. Five random crystal orientations selected from EBSD data were used for the present study (see Figure 2). For ellipsoidal voids 3 different defect orientations $\left(0^{\circ}, 45^{\circ}\right.$, and $90^{\circ}$ from loading axis) were used. Details of the above and some representative half sectioned models are shown in Figure 2. All of the 3D RVE models were modelled and meshed using ABAQUS/CAE (version 6.12) with reduced-integrated, first-order linear brick elements (C3D8R) for local model and first-order linear brick elements (C3D8) for nonlocal model. All simulations were performed using ABAQUS/Standard analysis method. A detailed mesh sensitivity analyses was performed and it was found that highly refined mesh is required in the surroundings of the void keeping the aspect ratio of individual elements under certain limits so that elements are as cubical as possible. Total numbers of elements used in the individual model were dependent on the void size and geometry, which ranged from $11272-25771$ elements. All simulations were performed using displacement controlled tests $[28,30,44,57,65]$ to avoid any instabilities of the calculations. As discussed in the previous section, many authors keep the volume averaged stress triaxiality constant throughout the simulation which is a more realistic approach; however this requires a computationally intensive iterative solution procedure to estimate the boundary conditions. Displacement controlled test used in the present study and in the past $[28,30,44,57,65]$ provides a way to simulate high stress 
triaxiality (though varying) which is more close to necking in tensile specimen. For the present study displacements in lateral direction were tuned to keep applied triaxialities constant, i.e. $1 / 3,1,2,3$, while volume averaged triaxiality varied depending on the void growth throughout the simulation. This assumption is appropriate for the present study as it is aimed to find a correlation among void growth, initial porosity, initial void size, plastic anisotropy, varying triaxiality and local/nonlocal size effects.
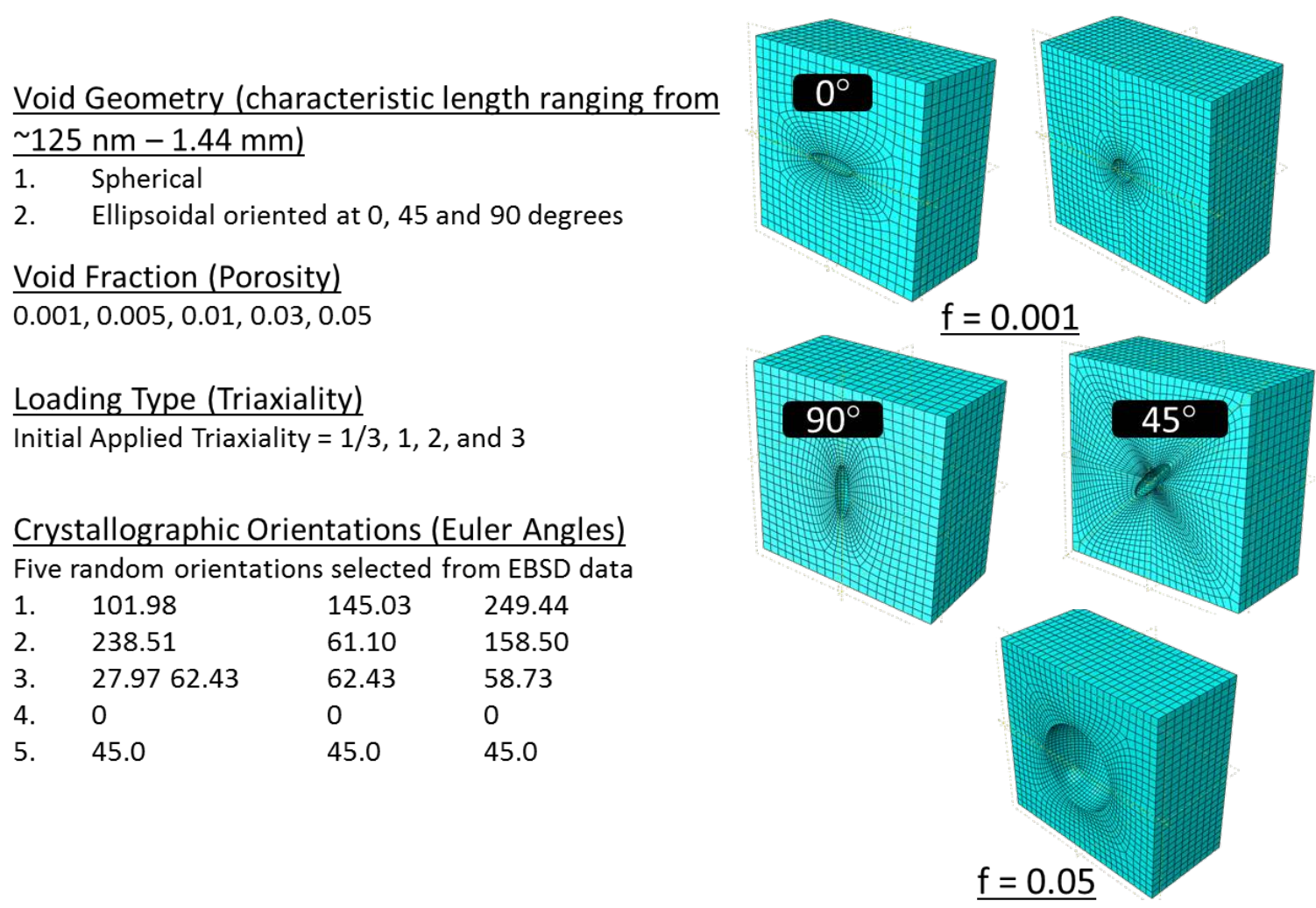

Figure 2: Test matrix for RVE based CPFEM Study with half sectioned model

\section{Result and Discussion}

\subsection{Effect of Applied Loading, Void Shape and Orientation on Void Growth using Local CPFEM}

To investigate the effect of loading types, four different applied triaxialities $(1 / 3,1,2,3)$ were simulated for previously discussed initial porosities, sizes and shapes of voids. Effect of applied strain and triaxiality on normalised porosity (void fraction) evolution for different void sizes and shapes is plotted in Figure 3 , we only present results for two initial porosities of 0.001 and 0.01 for brevity. Here the growth is plotted against equivalent strains, given by:

$\epsilon_{e q}=\frac{1}{\sqrt{3}} \sqrt{2 \times\left(\epsilon_{11}^{2}+\epsilon_{22}^{2}+\epsilon_{33}^{2}\right)+\epsilon_{12}^{2}+\epsilon_{23}^{2}+\epsilon_{13}^{2}}$

Where each of the strain components are volume averaged over all elements.

Similarly, only the results of two different void shapes, namely spherical and ellipsoidal voids with orientations of $0^{\circ}$ and $45^{\circ}$ from loading axis, have been presented. It should be noted 
that all the results shown in Figure 3 are for same crystal orientation (Orientation 1, please see Figure 2). It is found that in all the cases (irrespective of initial void size, shape or orientation), as the applied strain is increased the void size increases exponentially. Figure 3 $(a, b)$ shows the normalised void fraction evolution of two different initial porosities for spherical voids. It is found that larger voids (higher initial porosity) grow more, i.e. reaching to higher porosity value, than smaller voids at higher triaxialities.

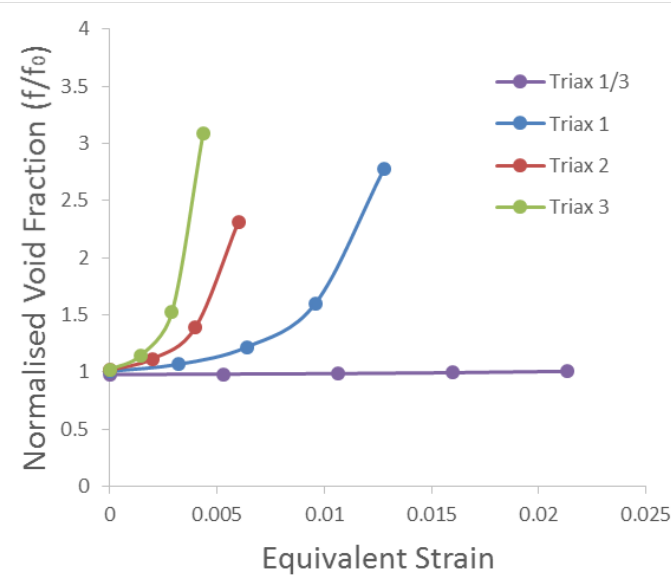

(a) fo $=0.001 ;$ Orientation 1; Spherical Void

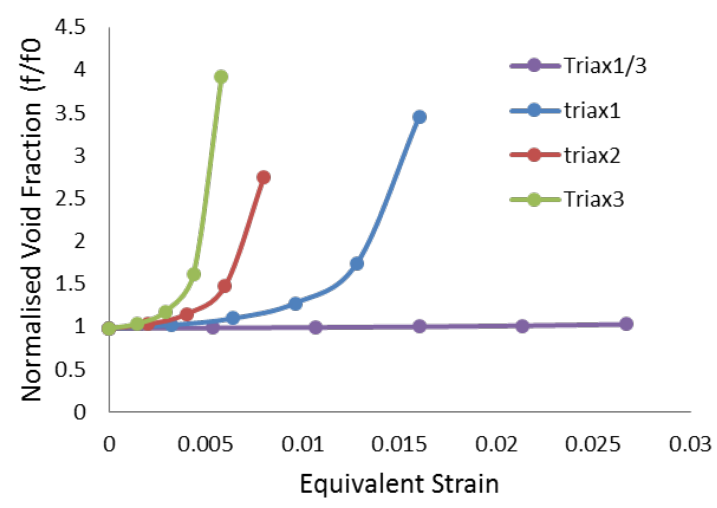

(c) fo $=0.001$; Orientation 1; Ellipsoidal $0^{\circ}$

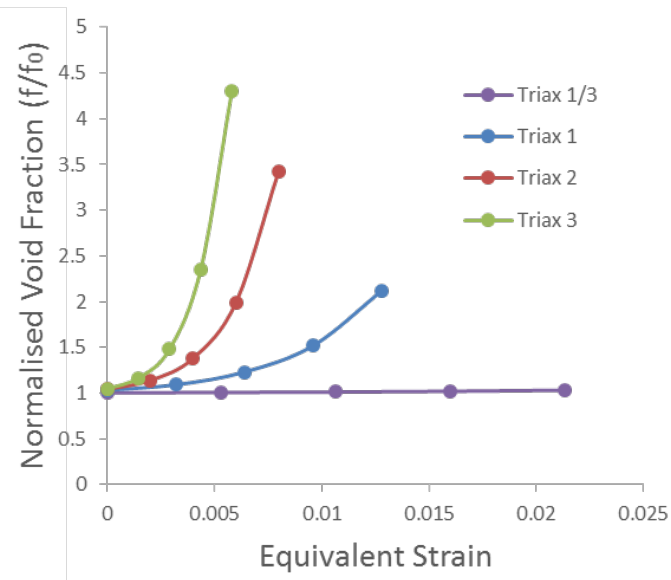

(b) fo $=0.01$; Orientation 1; Spherical Void

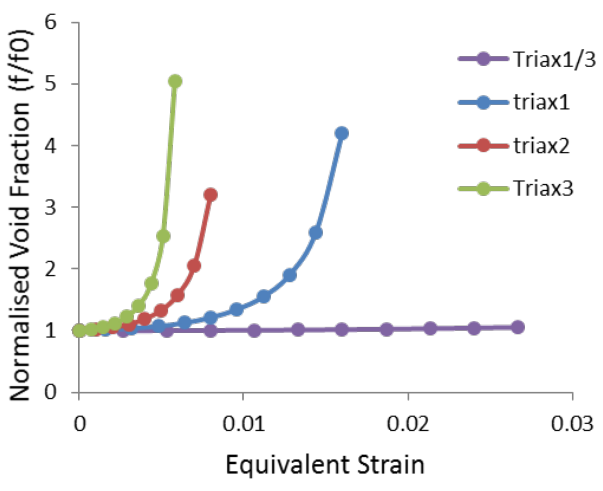

(d) fo $=0.001$; Orientation 1; Ellipsoidal $45^{\circ}$

Figure 3: Effect of triaxiality and applied strain on void growth for different porosities and void shapes and sizes

Figure 3 (c, d) shows the plots of the normalised void fraction evolution as a function of applied strain and applied triaxiality for ellipsoidal voids with void orientations of $0^{\circ}$ and $45^{\circ}$. Results show a similar trend as for the spherical void discussed above, i.e. exponential or power law dependent void growth with respect to the applied strain and higher growth rate with increasing applied triaxiality. Orientation of the ellipsoidal void with reference to the loading axis didn't show a significant difference as far as the void growth is concerned, this could be due to the aspect ratio selected for the ellipsoidal void, i.e. minor axes $=0.3 x$ major axis. It must be noted that the lower aspect ratios may result into different behaviour due to higher stress concentrations around the crack tips, however this is considered to be 
out of scope of the presented study since it will fall under the study of crack initiation and growth $[24,66]$ rather than void growth.

In order to better quantify the relationship among initial applied triaxiality, applied strain and porosity evolution; surface plots are shown in Figure 4 for two different initial porosities and two different initial void shapes (spherical and ellipsoidal). These plots show that void growth is slightly less sensitive to applied triaxiality than applied strain irrespective of the void size, shape and orientation for the present material.

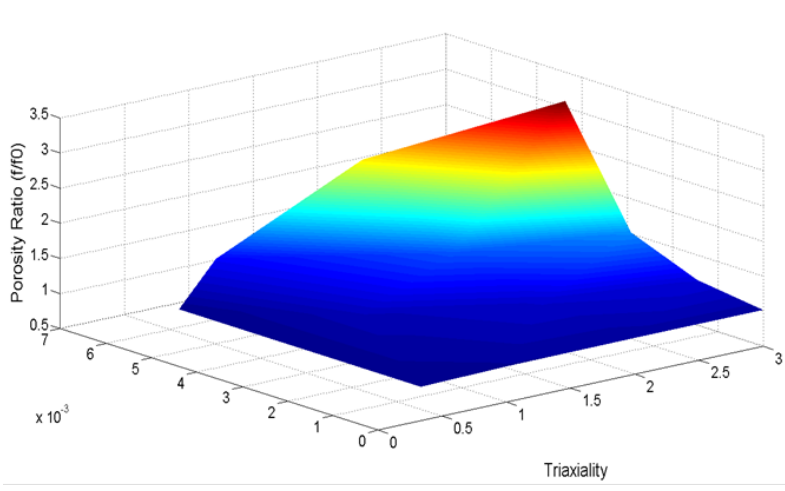

(a) fo 0.001 ; Orientation 1; Spherical Void

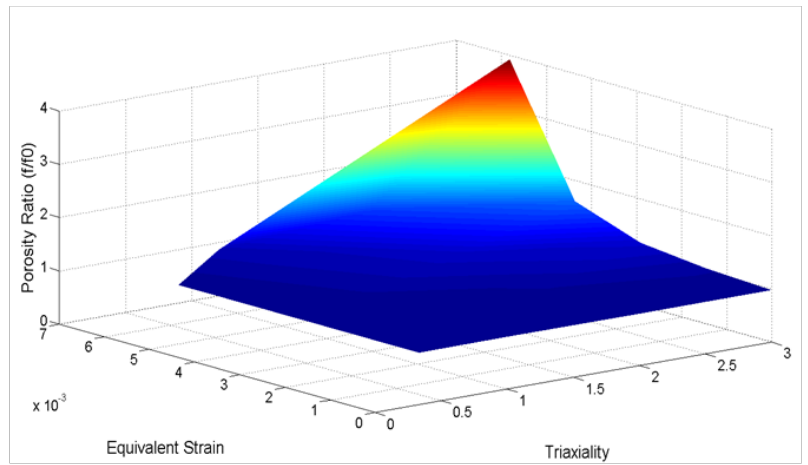

(c) fo $=0.001$; Orientation 1; Ellipsoidal $0^{\circ}$

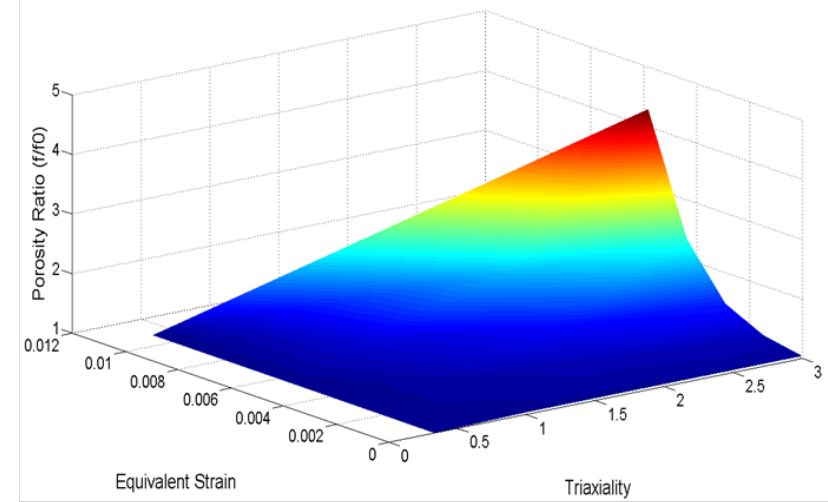

(b) fo $=0.01$; Orientation 1; Spherical Void

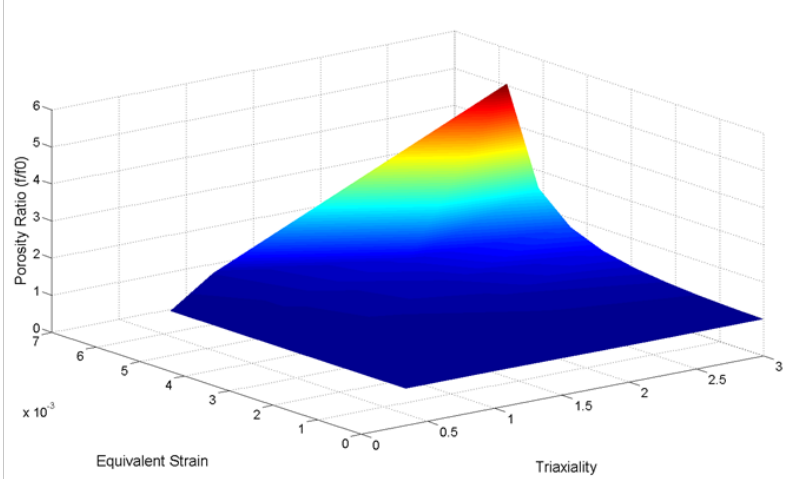

(d) fo $=0.001$; Orientation 1; Ellipsoidal $45^{\circ}$

Figure 4: Surface plot of the void growth as a function of triaxiality and applied strain for different porosities and void shapes and sizes

\subsection{Effect of Initial Porosity and Void Size on Void Growth using Local CPFEM}

In order to understand the interaction and interdependency of the void growth, initial porosity, initial void size, and loading triaxiality; Figure 5 shows the plots of the normalised void fraction evolution for spherical voids as a function of applied strain for two different initial porosities, crystal orientations and four different applied triaxialities. It can be inferred from Figure 5 that normalised void fraction increases at the same rate for all initial porosities until a certain applied strain value after which voids with higher initial porosities grow slower than the lower initial porosity voids. It was found that the overall volume averaged triaxiality in the RVE started to decrease significantly (Figure 6) due to the void growth after certain amount of applied strain which is found to be the reason for the higher 
growth rate of smaller voids after a certain amount of applied strain. It is also found that the strain at which the separation of the two curves occur reduces, with the increasing applied triaxiality, this is again linked to the strain after which volume averaged triaxiality decrease significantly. Similar trend was found for other orientations, for e.g. orientation 3 (Figure $5 b)$.

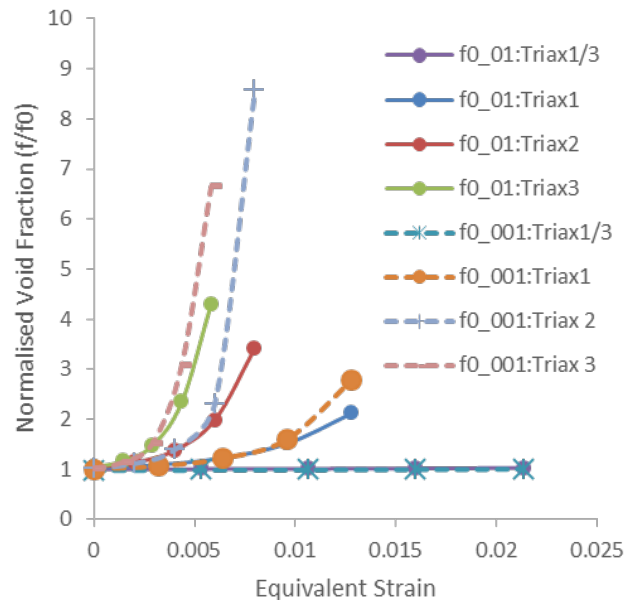

(a) Orientation 1; Spherical Void

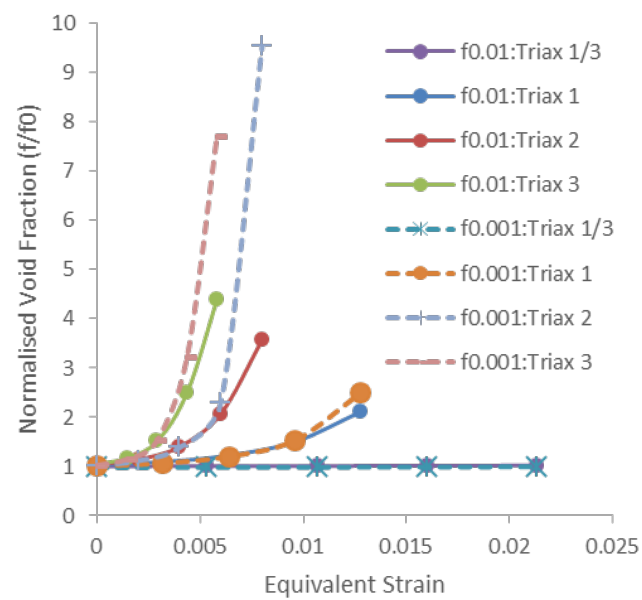

(b) Orientation 3; Spherical Void

Figure 5: Effect of Initial porosity and void size on normalised void fraction evolution

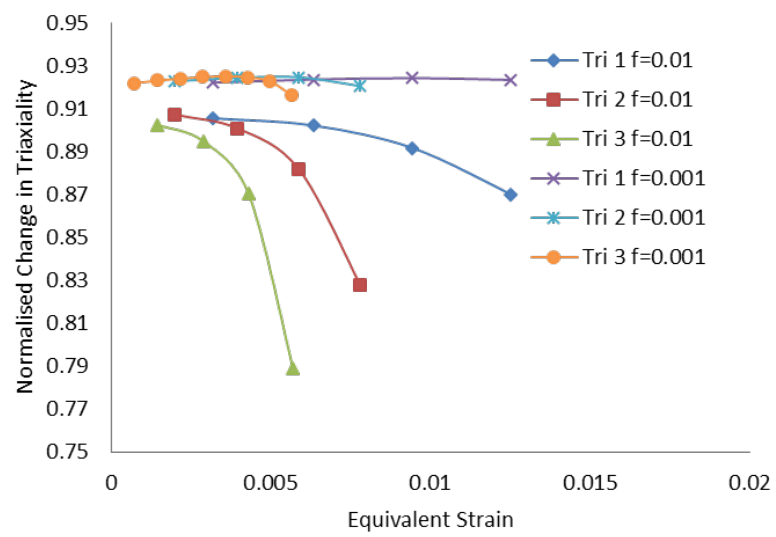

Figure 6: Normalised change in volume averaged triaxiality for two different porosities and 3 different applied triaxialities

\subsection{Effect of Plastic Anisotropy on Void Growth using Local CPFEM}

Figure 7 shows the plots of the normalised void fraction evolution for spherical voids with respect to applied strain, initial crystal orientation and load triaxiality. It can be inferred from the Figure $7(a, b, c)$ that plastic anisotropy (initial crystal orientation) has significant impact on the void growth for low applied triaxialities and as this is increased the effect of plastic anisotropy diminishes which are consistent with the results reported in literature (for e.g. [31]). In the present study, similar effects have been found for other void shapes, namely ellipsoidal voids and are not repeated here for brevity. 


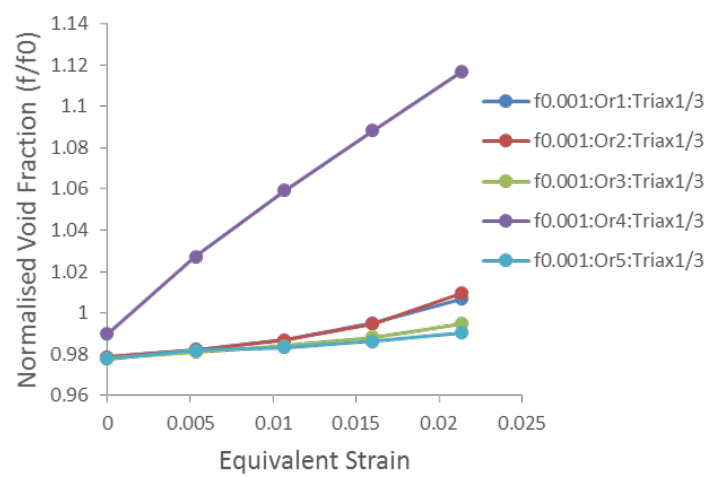

(a) Triaxiality $=1 / 3 ;$ Spherical Voids

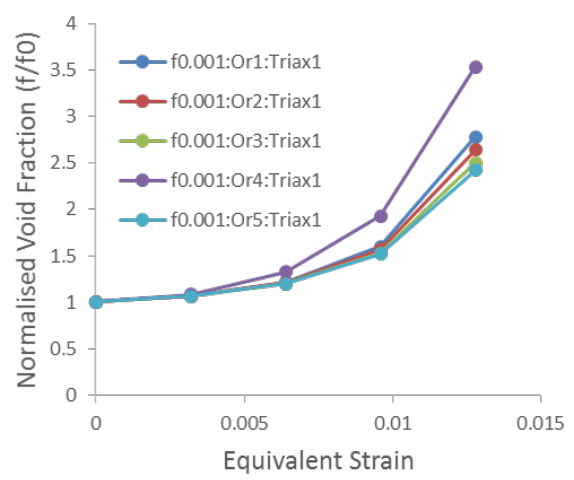

(b) $\underline{\text { Triaxiality }=1 \text { Spherical Voids }}$

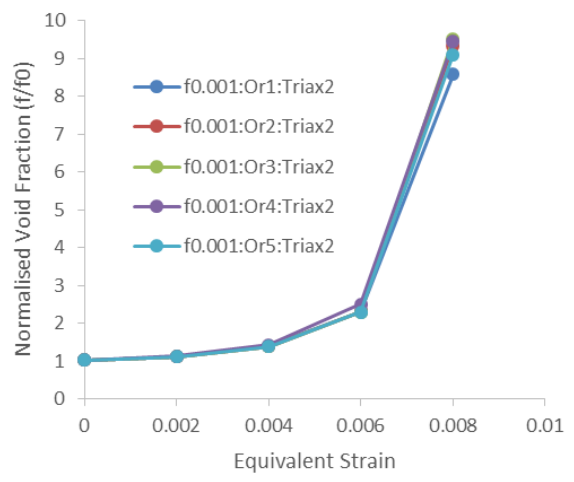

(c) Triaxiality $=3$ Spherical Voids

Figure 7: Effect of Initial crystal orientation and triaxiality on normalised void fraction evolution for spherical voids

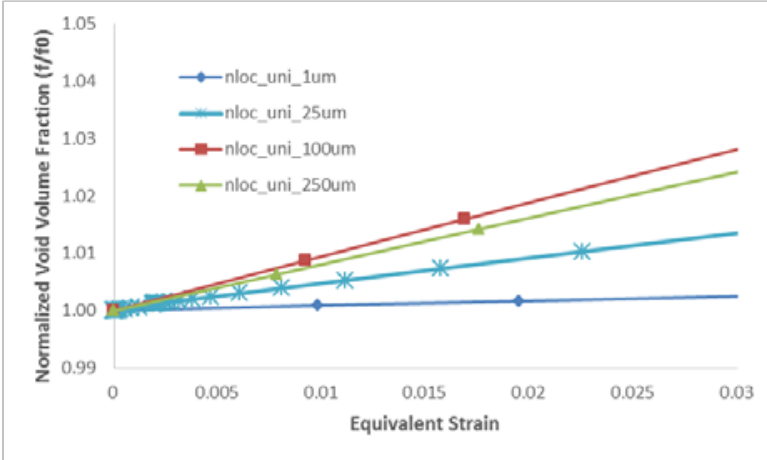

(a) Uniaxial; Spherical Voids; Non-Local Model

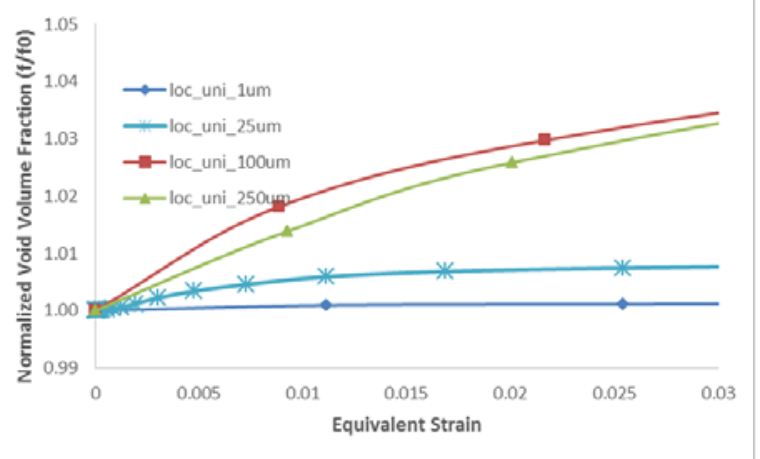

(b) Uniaxial; Spherical Voids; Local Model

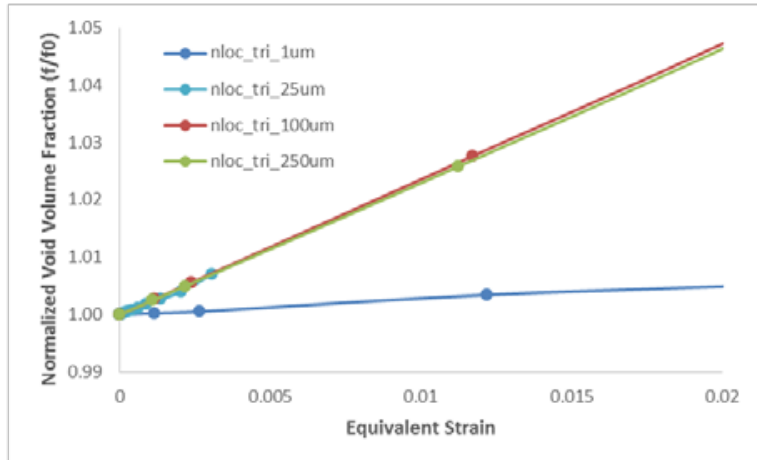

(c) Triaxial=1; Spherical Voids; Non-Local Model

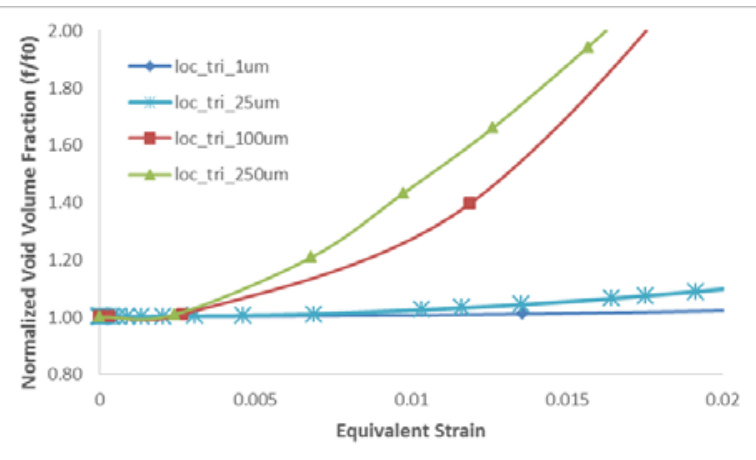

(d) Triaxial=1; Spherical Voids; Local Model 
Figure 8: Effect of void size on void growth using local and non-local CPFEM

\subsection{Effect of Void Size on Void Growth using Local and Non-Local CPFEM}

Figure 8 shows the plots of the normalised void fraction with respect to the applied strain for uniaxial and triaxiality=3 using local and non-local CPFEM. It can be inferred from Figure $8 \mathrm{a}$ and $\mathrm{b}$, for uniaxial case, the nonlocal model predicts more resistance to void growth, i.e. void fraction evolution is found to be lower than the one obtained through local model, however the effect of MSG based strain gradient effects are very small for all void sizes used. For the case of triaxial loading the void growth is found to decrease significantly due to strain gradient effects, i.e. voids show more resistance to growth with reductions up to $48 \%$ in growth. For voids larger than $700 \mu \mathrm{m}$ showed that the applied triaxiality is increased (Figure 8) the effect of strain gradient (non-local) diminishes due to large scale of plasticity around void due to its growth.

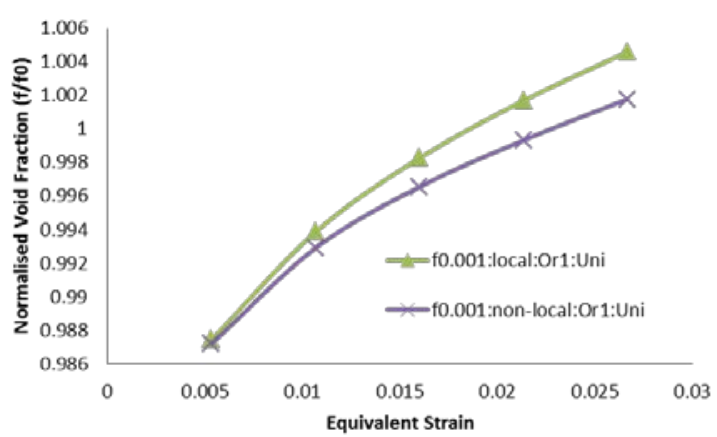

(a) $\underline{\text { Triaxiality }=1 / 3 ; \text { Spherical Voids }}$

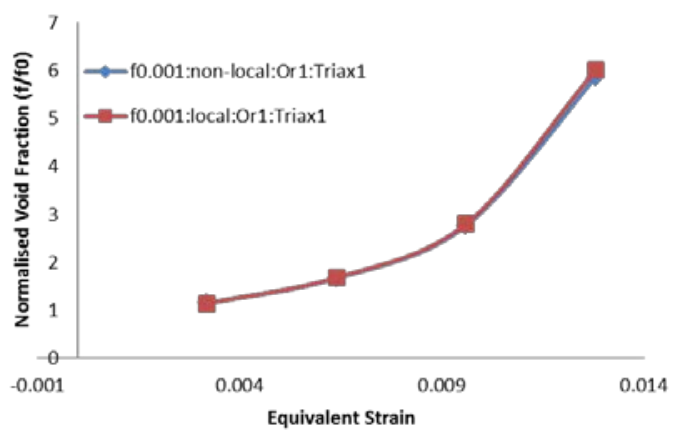

(b) $\underline{\text { Triaxiality }=1 ; \text { Spherical Voids }}$

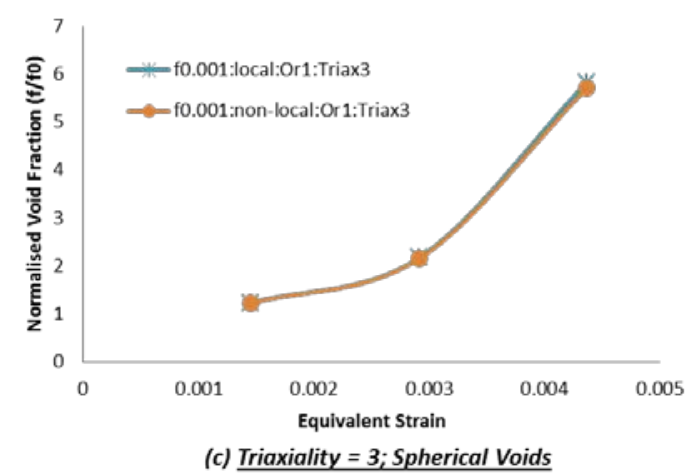

Figure 9: Effect of Strain gradients on void growth for void size $=800 \mu \mathrm{m}$

\subsection{Lattice Orientation Evolution with Void Growth using Local CPFEM}

Lattice orientation evolution has been plotted in Figure 10 (spherical voids) and Figure 11 (ellipsoidal voids) as $\{111\}$ pole figures for different initial porosities, loading types and crystal orientations. Figure 10 shows that lattice rotation is small for uniaxial cases irrespective of void size and orientation which is due to the small amount of void growth. It can also be inferred from Figure 10 that lattice rotation magnitude and direction is strongly dependent on the initial crystal orientation and initial loading triaxiality, i.e. as the initial triaxiality is increased the amount of lattice rotation increases due to larger amount of void growth. It is found that lattice rotation and void growth are directly related to each other 
and higher the void growth, higher is the lattice rotation and vice versa. As discussed in the previous sections, during deformation of material with void; voids and defects try to reduce the overall triaxiality (see Figure 6 ) of the material by dissipating energy locally through its growth (which is the reason for higher void growth for higher triaxialities). The same has been found in the present study that most of the lattice rotation was found to occur in the vicinity of the defect (see Figure 12).

Figure 11 shows the plots of the lattice orientation evolution with increasing level of initial triaxiality and for different crystal and defect orientations. It was discussed in section 3.1 that orientation of the ellipsoidal void with reference to the loading axis didn't show a significant difference as far as the void growth is concerned, however lattice rotation plots in Figure 11 show that initial crystal and defect orientation show different amount and directions of lattice rotations. The effect of defect orientation diminishes as the triaxiality is increased. Though the lattice orientation evolution is different for different initial crystal and defect orientation, it must be noted that overall void growth is not affected by this as void growth is directly related to energy dissipation to minimise triaxiality effects. 


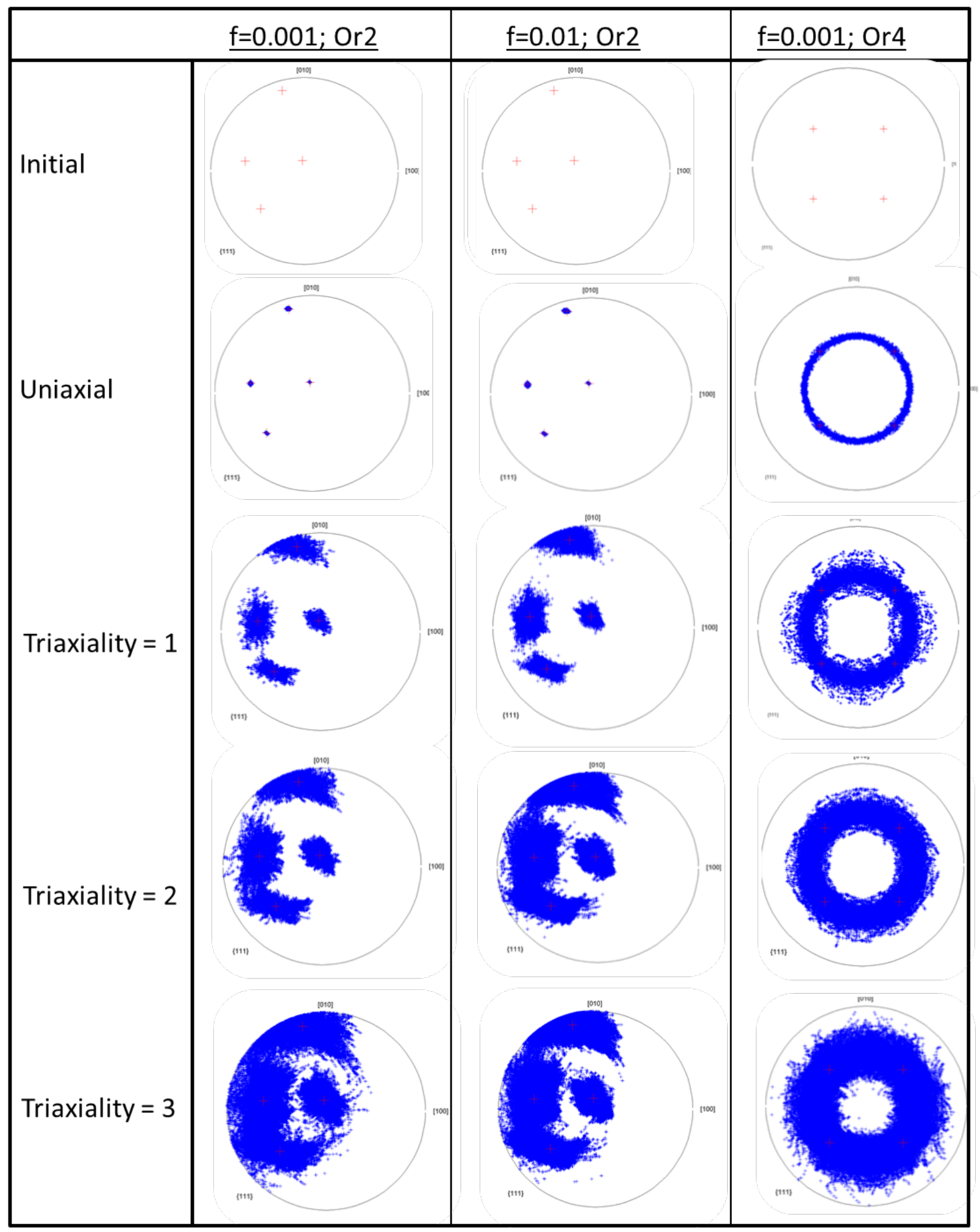

Figure 10: $\{111\}$ pole figures single crystal RVE with spherical void showing initial (top) and final orientations for different loading types, porosities and orientations 


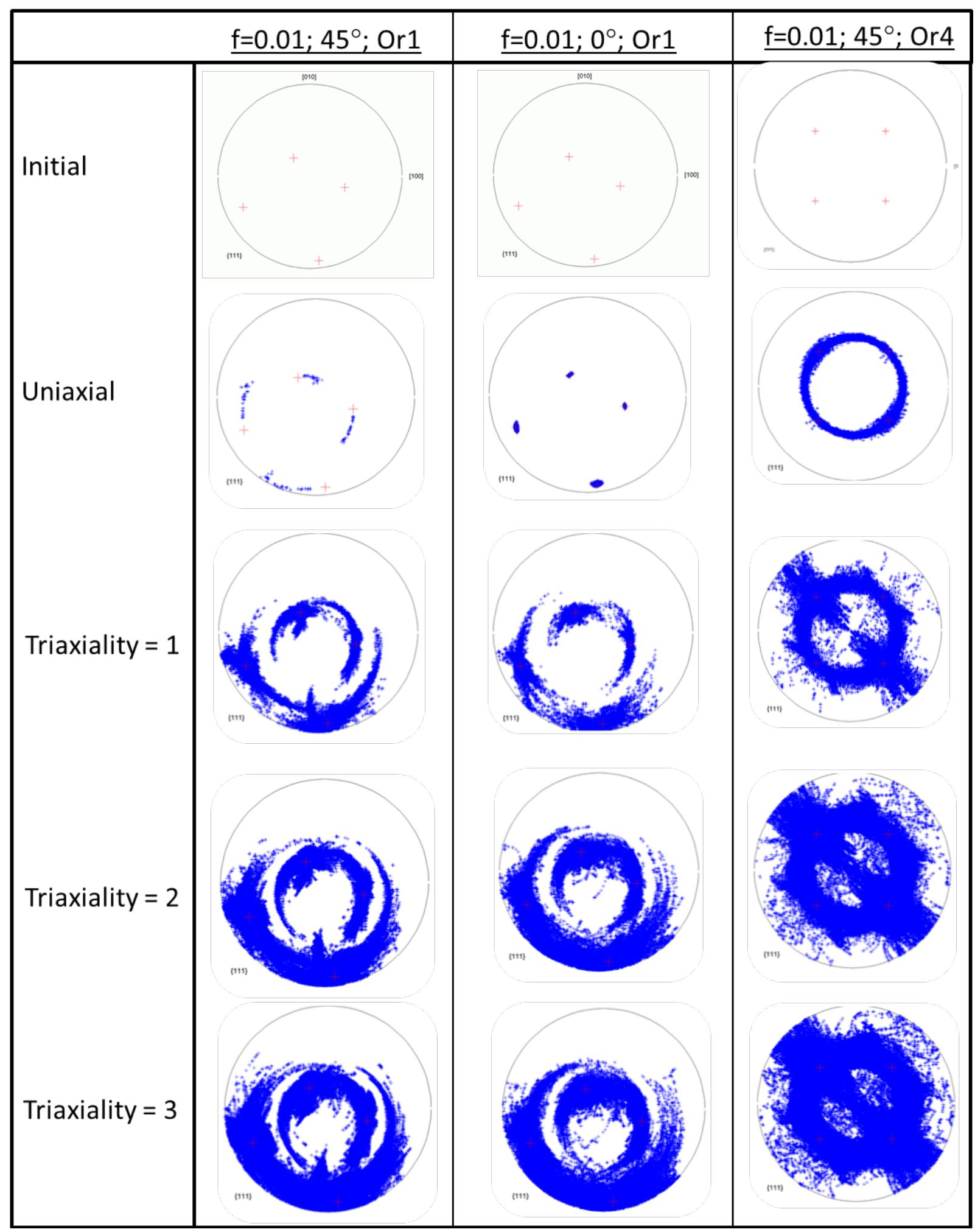

Figure 11: 111\} pole figures single crystal RVE with ellipsoidal void showing initial (top) and final orientations for different loading types, porosities and orientations 


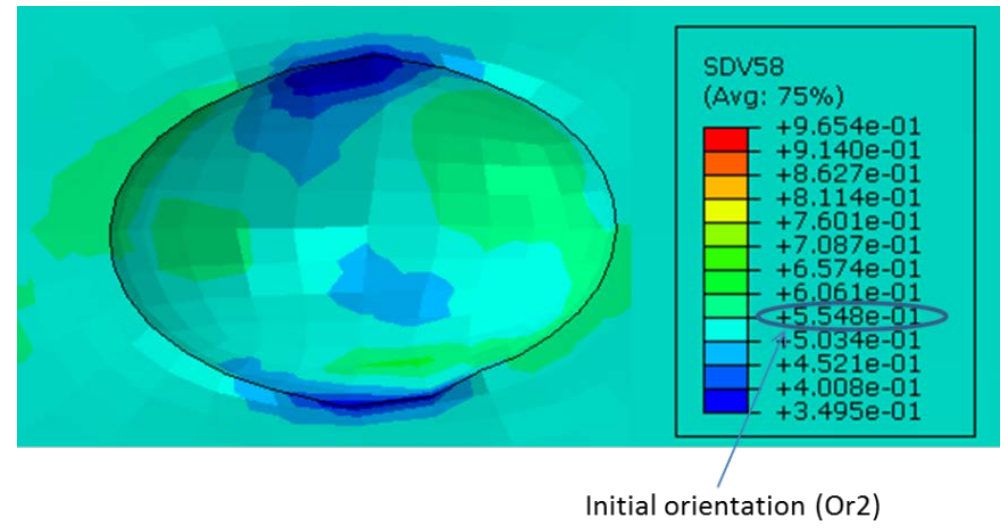

Figure 12: Lattice rotation (direction cosines) for initial porosity of 0.001; initial triaxiality= 1; Orientation 2 (showing most of the rotation locally in the vicinity of the void)

\subsection{Correlation among Void Growth, Stress Triaxiality, and Applied Strain}

Based on the results presented in previous sections, a generalised correlation among void growth, stress triaxiality and applied strain has been deduced. This correlation is based on the conclusion that exponential or power-law relation exists between void growth, applied strains and stress triaxiality (for details see Figure 4 and relevant text). Using this analogy the correlation is given by

Normalised void volume fraction $=\frac{f}{f_{0}}=1+X^{A} \cdot\left(\frac{\varepsilon_{\mathrm{eq}}}{C}\right)^{B}$

Where $X=\frac{\sigma_{h}}{\sigma_{e}}$ is the stress triaxiality, $\varepsilon_{e q}$ is the equivalent strain, while $A$ and $B$ are material parameters which depends on single crystal orientation and initial void size or porosity. $f$ and $f_{0}$ are the current and initial porosities, respectively. For spherical voids, $f$ is given by $\frac{4}{3} \pi r^{3}$ with $r$ being the radius of the void. It must be noted that in the past void growth is mentioned to be an exponential function of the stress triaxiality (for details please see [10] and references there in) which is in conjunction to the above relation.

Material parameters $A$ and $B$ were found (Table 2 ) for two initial porosities ( 0.001 and 0.01 ) for a spherical void by fitting the surface over the results already presented in Figure 4 . Also the fitted surfaces are shown in Figure 13, where the meshed surface represents the one obtained by parameter fitting.

Table 2: Material Parameter for Normalized void volume fraction

\begin{tabular}{|c|c|c|c|}
\hline Initial Porosity & A & B & C \\
\hline 0.001 & 3. & 4.5 & 0.01 \\
\hline 0.01 & 3. & 3. & 0.015 \\
\hline
\end{tabular}



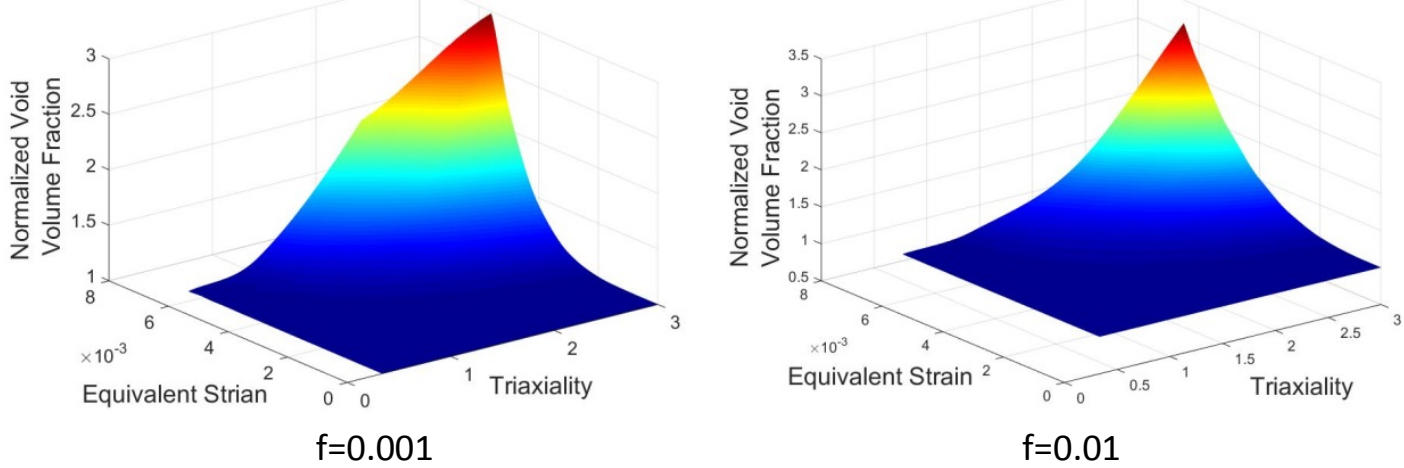

Figure 13: Fitted surface of actual RVE simulation and equation (8) for spherical voids and orientation 1

\section{Conclusion}

A systematic rigorous three dimensional crystal plasticity based study to better understand the role of voids and defects during deformation of aluminium alloy single crystal has been presented. The effect of void geometry, void and crystal orientation, applied strain, initial porosity, and initial loading triaxiality on void growth and crystal deformation evolution has been presented. An effort was put to reveal insights about the relationship among void growth, initial porosity, initial void geometry, plastic anisotropy, and local/nonlocal size effects. It is found that

- Void volume increases exponentially with increasing load irrespective of initial void size, shape or orientation

- Higher the triaxiality higher is the void growth

- For all initial porosities void growth rate was independent of initial porosity until a certain applied strain value after which voids with higher initial porosities grow slower due to the decrease in the overall triaxiality caused by void growth.

- Strong crystal orientation dependence of void growth was found for low triaxiality which diminished as the triaxiality was increased.

- Void growth is found to be slower with nonlocal models, however strain gradient (nonlocal) effect is found to diminish with increasing triaxialities for voids larger than $800 \mu \mathrm{m}$ for the present material.

- Lattice orientation evolution is found to be a strong function of initial crystal orientation and initial loading triaxiality

- Lattice rotation in the vicinity of void and void growth are found to be strongly related to each other, i.e. void grows to minimise the triaxiality causing lattice reorientation at and in the vicinity of void

- Effect of defect orientation on lattice rotation is found to be diminished as the triaxiality is increased

- Larger voids grow more to reach to a higher porosity value than smaller voids at higher triaxialities 
- Orientation of defect with reference to loading axes in the single crystal with same orientation didn't show any significant difference in growth

\section{Acknowledgements}

The author thankfully acknowledges the financial support of EPSRC funding (EP/L021714/1).

\section{References}

1. Singh D, Nageswara Rao $P$, Jayaganthan R. Microstructures and impact toughness behavior of Al 5083 alloy processed by cryorolling and afterwards annealing. Int. J. Miner. Metall. Mater. 2013;20:759-69.

2. Bradley GR, Hattingh DG, Yio TC, James MN. Crack Paths in Friction Stir Welded 5083H321 and 5383- H321 Aluminium Alloys.

3. Gurland J, Plateau J. The mechanism of ductile rupture of metals containing inclusions. Trans. ASM. 1963;56:442-54.

4. Beachem CD. An electron fractographic study of the influence of plastic strain conditions upon ductile rupture processes in metals. Trans. ASM. 1963;56:318-26.

5. Rogers HC. The tensile fracture of ductile metals. Trans. Met. Soc. AIME. 1960;218:498506.

6. McClintock FA. A Criterion for Ductile Fracture by the Growth of Holes. J. Appl. Mech. 1968;35:363-71.

7. Rice JR, Tracey DM. On the Ductile Enlargement of Voids in Triaxial Stress Fields. J. Mech. Phys. Solids. 1969;17:201-17.

8. Needleman A. Void growth in an elastic-plastic medium. J. Appl. Mech. 1972;39:964-70.

9. Nemat-Nasser S, Hori M. Void collapse and void growth in crystalline solids. J. Appl. Phys. 1987;62:2746-57.

10. Liu B, Qiu X, Huang Y, Hwang KC, Li M, Liu C. The size effect on void growth in ductile materials. J. Mech. Phys. Solids. 2003;51:1171-87.

11. Kysar JW, Gan YX, Mendez-Arzuza G. Cylindrical void in a rigid-ideally plastic single crystal. Part I: Anisotropic slip line theory solution for face-centered cubic crystals. Int. J. Plast. 2005;21:1481-520.

12. W KJ, X GY. Void growth in fcc and bcc single crystals. ICF XI - 11th Int. Conf. Fract. 2005;

13. Li Z, Steinmann P. RVE-based studies on the coupled effects of void size and void shape on yield behavior and void growth at micron scales. Int. J. Plast. 2006;22:1195-216.

14. Andersson $\mathrm{H}$. Analysis of a model for void growth and coalescence ahead of a moving crack tip. J. Mech. Phys. Solids. 1977;25:217-33.

15. Tvergaard V. Influence of Voids on Shear Band Instability Under Plane Strain Conditions. Int. J. Fract. 1981;17:389-407. 
16. Chen LG, Howard IC. The effect of strain softening void. J. Mech. Phys. Solids. 1983;31:85-102.

17. Li Guo Chen, Howard IC. The sensitivity of the macroscopic consequences of void growth in ductile materials to various mechanical and geometrical micro-parameters. Int. J. Solids Struct. 1983;19:1089-98.

18. Bourcier RJ, Koss DA, Smelser RE, Richmond O. The influence of porosity on the performance and properties of parachutes. Acta Metall. 1986;34:2443-53.

19. Koplik J, Needleman A. Void growth and coalescence in porous plastic solids. Int. J. Solids Struct. 1988;24:835-53.

20. Hom CL, McMeeking RM. Void growth in elastic-plastic materials. ASME J. Appl. Mech. 1989;56:309-17.

21. Worswick MJ, Pick RJ. Void growth and constitutive softening in a periodically voided solid. J. Mech. Phys. Solids. 1990;38:601-25.

22. Needleman A, Tvergaard V, Giessen E Van Der. Evolution of Void Shape and Size in Creeping Solids. Int. J. Damage Mech. 1995;4:134-52.

23. Kuna M, D. Z. Sun. Three-dimensional cell model analyses of void growth in ductile materials. Int. J. Fract. 1996;81:235-58.

24. Tvergaard V, Hutchinson JW. Two mechanisms of ductile fracture: Void by void growth versus multiple void interaction. Int. J. Solids Struct. 2002;39:3581-97.

25. Li Z, Guo W. The influence of plasticity mismatch on the growth and coalescence of spheroidal voids on the bimaterial interface. Int. J. Plast. 2002;18:249-79.

26. O'Regan TL, Quinn DF, Howe M a., McHugh PE. Void growth simulations in single crystals. Comput. Mech. 1997;20:115-21.

27. Orsini VC, Zikry M a. Void growth and interaction in crystalline materials. Int. J. Plast. 2001;17:1393-417.

28. Ohashi T. Crystal plasticity analysis of dislocation emission from micro voids. Int. J. Plast. 2005;21:2071-88.

29. Potirniche GP, Hearndon JL, Horstemeyer MF, Ling XW. Lattice orientation effects on void growth and coalescence in fcc single crystals. Int. J. Plast. 2006;22:921-42.

30. Liu WH, Zhang XM, Tang JG, Du YX. Simulation of void growth and coalescence behavior with 3D crystal plasticity theory. Comput. Mater. Sci. 2007;40:130-9.

31. Yerra SK, Tekog̃lu C, Scheyvaerts F, Delannay L, Van Houtte $P$, Pardoen T. Void growth and coalescence in single crystals. Int. J. Solids Struct. 2010;47:1016-29.

32. Ha S, Kim K. Void growth and coalescence in f.c.c. single crystals. Int. J. Mech. Sci. Elsevier; 2010;52:863-73.

33. Huang $M$, Li Z, Wang C. Discrete dislocation dynamics modelling of microvoid growth 
and its intrinsic mechanism in single crystals. Acta Mater. 2007;55:1387-96.

34. Segurado J, Llorca J. An analysis of the size effect on void growth in single crystals using discrete dislocation dynamics. Acta Mater. Acta Materialia Inc.; 2009;57:1427-36.

35. Pushkareva M, Adrien J, Maire E, Segurado J, Llorca J, Weck A. Three-dimensional investigation of grain orientation effects on void growth in commercially pure titanium. Mater. Sci. Eng. A. 2016;671:221-32.

36. Tvergaard V, Needleman A. Nonlocal effects on localization in a void-sheet. Int. J. Solids Struct. 1997;34:2221-38.

37. Tvergaard V, Niordson C. Nonlocal plasticity effects on interaction of different size voids. Int. J. Plast. 2004;20:107-20.

38. Hütter G, Zybell L, Kuna M. Size effects due to secondary voids during ductile crack propagation. Int. J. Solids Struct. Elsevier Ltd; 2014;51:839-47.

39. Zybell L, Hütter G, Linse T, Mühlich U, Kuna M. Size effects in ductile failure of porous materials containing two populations of voids. Eur. J. Mech. A/Solids. Elsevier Masson SAS; 2014;45:8-19.

40. Shu JY. Scale-dependent deformation of porous single crystals. Int. J. Plast. 1998;14:1085-107.

41. Huang Y, Gao H, Nix WD, Hutchinson JW. Mechanism-based strain gradient plasticity-II. Analysis. J. Mech. Phys. Solids. 2000;48:99-128.

42. Borg U, Kysar JW. Strain gradient crystal plasticity analysis of a single crystal containing a cylindrical void. Int. J. Solids Struct. 2007;44:6382-97.

43. Borg U, Niordson CF, Kysar JW. Size effects on void growth in single crystals with distributed voids. Int. J. Plast. 2008;24:688-701.

44. Liu WH, He ZT, Tang JG, Hu ZJ, Cui DT. The effects of load condition on void coalescence in FCC single crystals. Comput. Mater. Sci. 2012;60:66-74.

45. Liu W, Huang H, Tang J. FEM simulation of void coalescence in FCC crystals. Comput. Mater. Sci. Elsevier B.V.; 2010;50:411-8.

46. Hill R, Rice JR. Constitutive analysis of elastic-plastic crystals at arbitrary strain. J. Mech. Phys. Solids. 1972;20:401-13.

47. Asaro RJ. Crystal Plasticity. J. Appl. Mech. American Society of Mechanical Engineers; 1983;50:921.

48. Bassani JL, Wu T-Y. Latent Hardening in Single Crystals II. Analytical Characterization and Predictions. Proc. R. Soc. A Math. Phys. Eng. Sci. 1991;435:21-41.

49. Cuitino AM, Ortiz M. A material-independent method for extending stress update algorithms from small-strain plasticity to finite plasticity with multiplicative kinematics. Eng. Comput. 1992;9:437-51. 
50. Kameda T. Three dimensional dislocation-based crystalline constitutive formulation for ordered intermetallics. Scr. Mater. 1998;38:631-6.

51. Siddiq A, El Sayed T. A phenomenological variational multiscale constitutive model for intergranular failure in nanocrystalline materials. Mater. Lett. 2013;107:56-9.

52. Siddiq A, Sayed T El. A thermomechanical crystal plasticity constitutive model for ultrasonic consolidation. Comput. Mater. Sci. Elsevier; 2012;51:241-51.

53. Siddiq A, Schmauder S. Interface fracture analyses of a bicrystal niobium/alumina specimen using a cohesive modelling approach. Model. Simul. Mater. Sci. Eng. 2006;14:1015-30.

54. Siddiq A, Schmauder S, Huang Y. Fracture of bicrystal metal/ceramic interfaces: A study via the mechanism-based strain gradient crystal plasticity theory. Int. J. Plast. Elsevier; 2007;23:665-89.

55. Siddiq A, Schmauder S, Ruehle M. Niobium/alumina bicrystal interface fracture: A theoretical interlink between local adhesion capacity and macroscopic fracture energies. Eng. Fract. Mech. Elsevier; 2008;75:2320-32.

56. Siddiq A, El Sayed T. Acoustic softening in metals during ultrasonic assisted deformation via CP-FEM. Mater. Lett. Elsevier; 2011;65:356-9.

57. Niordson CF, Kysar JW. Computational strain gradient crystal plasticity. J. Mech. Phys. Solids. Elsevier; 2014;62:31-47.

58. Marin EB. On the Formulation of a Crystal Plasticity Model. Livermore; 2006.

59. Han C-S, Gao H, Huang Y, Nix WD. Mechanism-based strain gradient crystal plasticity-I. Theory. J. Mech. Phys. Solids. 2005;53:1188-203.

60. Demiral M, Roy A, Silberschmidt V V. Indentation studies in b.c.c. crystals with enhanced model of strain-gradient crystal plasticity. Comput. Mater. Sci. Elsevier B.V.; 2013;79:896902.

61. Marin EB, Dawson PR. Elastoplastic finite element analyses of metal deformations using polycrystal constitutive models. Comput. Methods Appl. Mech. Eng. 1998;165:23-41.

62. Demiral M, Roy A, El Sayed T, Silberschmidt V V. Influence of strain gradients on lattice rotation in nano-indentation experiments: A numerical study. Mater. Sci. Eng. A. 2014;608:73-81.

63. Busso EP, Meissonnier FT, O'Dowd NP. Gradient-dependent deformation of two-phase single crystals. J. Mech. Phys. Solids. 2000;48:2333-61.

64. Alsawy AB, Siddiq MA. Multiscale deformation and failure in aluminium alloy 6082-T6: Experiments and Modelling. Adv. Mater. World Congr. 2015.

65. Schacht T, Untermann N, Steck E. The influence of crystallographic orientation on the deformation behaviour of single crystals containing microvoids. Int. J. Plast. 2003;19:160526. 
66. McMeeking RM. Finite deformation analysis of crack-tip opening in elastic-plastic materials and implications for fracture. J. Mech. Phys. Solids. 1977;25:357-81. 